\title{
ASO Visual Abstract: Contribution of Genomics to the Surgical Management and Study of Oral Cancer
}

\author{
Zuzana Saidak, PhD ${ }^{1,2}$, Claire Lailler, PharmD ${ }^{1,2}$, Sylvie Testelin, MD, PhD ${ }^{1,3}$, Bruno Chauffert, MD, PhD $^{1,4}$, \\ Florian Clatot, $\mathrm{MD}, \mathrm{PhD}^{5,6}$, and Antoine Galmiche, $\mathrm{MD}, \mathrm{PhD}^{1,2}$ \\ ${ }^{1}$ UR7516 « CHIMERE », Université de Picardie Jules Verne, Amiens, France; ${ }^{2}$ Centre de Biologie Humaine, CHU \\ Amiens, Amiens, France; ${ }^{3}$ Department of Maxillofacial Surgery, CHU Amiens, Amiens, France; ${ }^{4}$ Department \\ of Oncology, CHU Amiens, Amiens, France; ${ }^{5}$ Centre Henri Becquerel, Rouen, France; ${ }^{6}$ INSERM U1245/team IRON, \\ Rouen, France
}

Genomics could be useful for the surgical management of OSCC for: (i) assessing the risk associated with potentially malignant oral lesions, (ii) tumor staging prior to surgery, (iii) predicting postoperative risk, (iv) optimizing longitudinal monitoring, and (v) predicting the efficacy of medical treatments (https://doi.org/10.1245/s10434-021-09904-0).
DISCLOSURE Florian Clatot: honoraria for expert testimony from Merck Serono, MSD, and BMS.

Publisher's NoteSpringer Nature remains neutral with regard to jurisdictional claims in published maps and institutional affiliations.

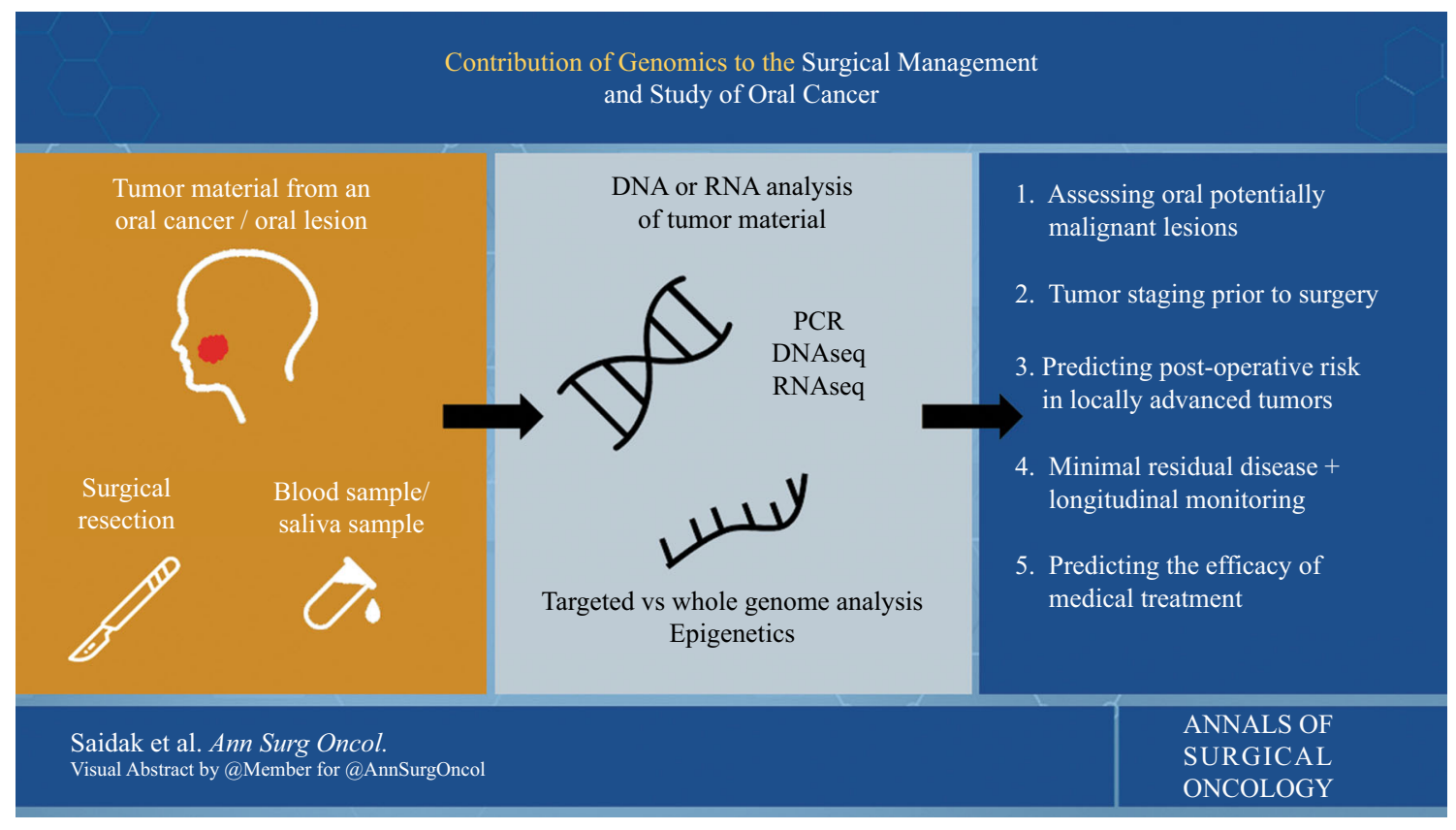

(C) Society of Surgical Oncology 2021, corrected publication 2021

Published Online: 26 April 2021

Z. Saidak, $\mathrm{PhD}$

e-mail: Saidak.Zuzana@chu-amiens.fr 